\title{
Superior Intelligence of Children Blinded from Retinoblastoma
}

\author{
M. WILLIAMS \\ From the School of Education, University of Birmingham *
}

It has been widely discussed amongst teachers of the blind that the children blinded from retinoblastoma are generally of above average intelligence. In an investigation into the intelligence of blind children, undertaken by the writer (1956), the IQ results obtained by this particular group of children suggested an above-average trend. The present investigation was therefore undertaken to study the intelligence of children at blind school whose blindness was due to retinoblastoma.

A retinoblastoma is a malignant tumour of the eye, originating from immature retina cells. The incidence has been variously estimated as being from 1 in 21,000 to 1 in 34,000 live births. Boys and girls are usually affected in about equal numbers.

Retinoblastoma may occur during fetal life and so be manifest at birth. In approximately $70 \%$ of cases the tumours are discovered before the age of 3 , and in the majority of the rest before 6 . In about $30 \%$ the tumours are bilateral, these being unconnected, independent foci of growth. The affected offspring of retinoblastoma survivors are particularly prone to bilateral tumours.

That there is a hereditary factor in retinoblastoma is well recognized. Extensive work on this subject has been done by the Children's Tumour Registry and the Department of Ophthalmology in the University of Manchester; Dr. J. K. Steward writes: 'In our series there are 152 children in the Manchester region with proven retinoblastoma between 1900 and 1960 . Of these, 101 were cured, and eight of these survivors have passed the disease to their progeny.' He further points out the impossibility of stating the proportion of patients without any antecedent family history of the disease but who would pass it on to their progeny, because if a survivor has only one or two children it cannot be said that his or her germ cells do not carry the

Received October 10, 1967.

* Miss M. Williams is Tutor to the Course for Training Teachers of Blind Children. Address: School of Education, P.O. Box 363, The University, Birmingham 15. gene. Francois (1961) instances the intensity of the gene reflected in its increased frequency in the second generation over the first, and in the third generation over the second, and, also, the appearance of retinoblastoma in both members of a pair of monozygotic twins as evidence supporting the hereditary nature of the disease. The mode of inheritance is said to be by a dominant gene with incomplete penetrance. There is no sex linkage. In the cases of direct transmission recorded by Dollfus and Auvert (1953) there are 35 cases of paternal heredity and 23 of maternal heredity. In cases of indirect transmission, the father was the carrier in 9 and the mother in 7.

The majority of retinoblastomas, however, have appeared sporadically, occurring as isolated events in otherwise healthy. families. Sporadic retinoblastomas are said to be due to a fresh mutation of genes. This mutation generally occurs in the affected person himself, which explains why he remains isolated in the family group of which he is a member. But, as mentioned above, he can pass the gene to his offspring; some authorities give the chance of his or her progeny being affected, if not clinically, at least genotypically, in the region of $45 \%$.

The survival rate of retinoblastoma in the Manchester series does not seem to have fluctuated to any great extent during the present century. On the other hand, according to returns (1955-62) from the nursery schools of The Royal National Institute for the Blind (R.N.I.B.) there is an increase in the actual number of retinoblastoma cases, and Sorsby (1966), in discussing this, says 'the increase in retinoblastoma may represent a therapeutically determined increase of a dominant affection: those who would formerly have died now live to become parents of a further generation of affected children'. A factor likely to have some bearing upon the increase is that the chances of marriage, particularly for the blind girl, are greater under today's social conditions than they were 20 or 30 years ago. 
TABLE I

Numbers of Subjects Tested at Each School for the Blind

\begin{tabular}{|c|c|c|c|}
\hline School & Type & $\begin{array}{c}\text { Retino- } \\
\text { blastoma } \\
\text { Subjects }\end{array}$ & $\begin{array}{c}\text { Non- } \\
\text { retino- } \\
\text { blastoma } \\
\text { Subjects }\end{array}$ \\
\hline $\begin{array}{ll}\text { Bridgend } & \ldots \\
\text { Bristol .. } & \ldots \\
\text { Chorleywood } & \ldots \\
\text { Dorton .. } & \ldots \\
\text { Lickey Grange } & \text {. } \\
\text { Linden Lodge } & \ldots \\
\text { Manchester } & \ldots \\
\text { Newcastle } & \ldots \\
\text { Rowton Castle } & \ldots \\
\text { St. Vincent's } & \ldots \\
\text { Sheffield } & \ldots \\
\text { Wavertree } & \ldots \\
\text { Worcester } & \ldots\end{array}$ & 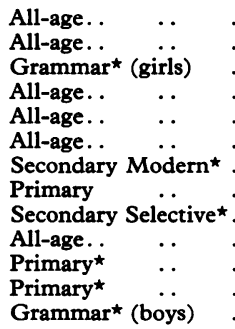 & $\begin{array}{r}3 \\
2 \\
4 \\
13 \\
4 \\
3 \\
1 \\
1 \\
1 \\
5 \\
5 \\
5 \\
3\end{array}$ & $\begin{array}{r}5 \\
4 \\
4 \\
10 \\
7 \\
8 \\
7 \\
5 \\
3 \\
6 \\
6 \\
7 \\
2\end{array}$ \\
\hline & & 50 & 74 \\
\hline
\end{tabular}

* Primary schools generally include children of 5-11 years, secondary and grammar schools of above 11 years, children with higher levels of intelligence going to the grammar schools.

\section{Investigation}

Purpose. The main purpose of this inquiry was (a) to find out whether the mean IQ of children blinded from retinoblastoma was higher than the mean IQ of children blinded from other causes, and (b) if so, to examine possible explanations in the light of this and other related research.

Subjects. In the selection of the sample of children to be tested the following procedures were adopted.

All schools for the blind in England and Wales were included except the Sunshine Nursery Schools and the special schools for the additionally handicapped blind.

Testing was confined to the age range 5 years and 6 months to 15 years and 5 months.

No blind child with an additional handicap was included: apart from this, every case of retinoblastoma was taken and a random $10 \%$ sample of the other blind children. The only measure of control exercised in the selection of non-retinoblastoma children was that groups of the main eye defects were randomized separately, in order to ensure that there would be included a variety of eye defects.

Table I shows the number of subjects tested at each school and Table II shows the age distribution.

Table I shows a disproportionately large number of retinoblastoma cases (13) at the Dorton School compared with other schools, probably a fortuitous occurrence.

The group of 50 children blinded from retinoblastoma constituted $6.3 \%$ of the total blind school population, excluding schools for the additionally handicapped, in the age range 5 years 6 months to 15 years 5 months. There were 27 boys and 23 girls.

In the non-reticuloblastoma group there were 37 boys and 37 girls.

In the retinoblastoma group there were only 5 cases with any residual vision, and in 4 of these this was in one eye only, the other having been excised. The visual acuity assessments were $4 / 60$ in 2 cases and $6 / 60,6 / 24$, in the other 2. The fifth case had a little vision in both eyes, recorded as $1 / 18$.

In the non-retinoblastoma group there were 45 children either totally blind or with only perception of light. The range of visual acuity in the other 29 children belonging to this group was from 'counts fingers' to $6 / 60$. The highest percentage of eye defects in the group was retrolental fibroplasia, which had affected $32.5 \%$ of the group. Other eye defects present were optic atrophy $(13.5 \%)$, congenital cataract $(9 \cdot 5 \%)$, buphthalmos $(6 \cdot 8 \%)$, microphthalmos $(6 \cdot 8 \%)$, congenital nystagmus $(5 \cdot 4 \%)$, retinal degeneration $(2 \cdot 7 \%)$, and uveitis $(2 \cdot 7 \%)$. The remaining $20 \%$ or so of the group consisted of small numbers of cases of various defects, including corneal dystrophy, endophthalmitis, and retinitis pigmentosa.

Onset of blindness in the retinoblastoma group had been mostly under the age of 3 years. Only in 3 cases had it been later, and these were all blind by the age of 6 .

Onset of blindness in the non-retinoblastoma group (45 of the 74 children were virtually blind) had been recorded as 'at birth', except in 5 cases, in which it had been later.

In addition to the children from blind school, a small sample was taken of sighted children from ordinary school. Four Birmingham schools were selected, which were reasonably representative of the social level met in blind schools: two primary, one secondary modern, and one bilateral. 30 boys and 30 girls were selected at

TABLE II

Distribution of Blind Subjects in Age-groups

\begin{tabular}{|c|c|c|c|c|c|c|c|c|c|c|c|c|c|c|}
\hline \multirow{2}{*}{\multicolumn{4}{|c|}{ Subjects }} & \multicolumn{10}{|c|}{ Age-groups (yr.) } & \multirow{2}{*}{ Total } \\
\hline & & & & $5 \frac{1}{2}-$ & $6 \frac{1}{2}-$ & $7 \frac{1}{2}-$ & $8 \frac{1}{2}-$ & $9 \frac{1}{2}-$ & $10 \frac{1}{2}-$ & $11 \frac{1}{2}-$ & $12 \frac{1}{2}-$ & $13 \frac{1}{2}-$ & $14 \frac{1}{2}+$ & \\
\hline $\begin{array}{l}\text { Retinoblastoma .. } \\
\text { Non-retinoblastoma }\end{array}$ & $\begin{array}{l}. \\
. .\end{array}$ & $\begin{array}{l}\ldots \\
\ldots\end{array}$ & $\begin{array}{l}\cdots \\
\cdots\end{array}$ & $\begin{array}{l}6 \\
3\end{array}$ & $\begin{array}{l}4 \\
4\end{array}$ & $\begin{array}{l}5 \\
9\end{array}$ & $\begin{array}{l}5 \\
9\end{array}$ & $\begin{array}{l}7 \\
6\end{array}$ & $\begin{array}{l}8 \\
4\end{array}$ & $\begin{array}{l}2 \\
7\end{array}$ & $\begin{array}{r}3 \\
10\end{array}$ & $\begin{array}{r}5 \\
10\end{array}$ & $\begin{array}{r}5 \\
12\end{array}$ & $\begin{array}{l}50 \\
74\end{array}$ \\
\hline
\end{tabular}

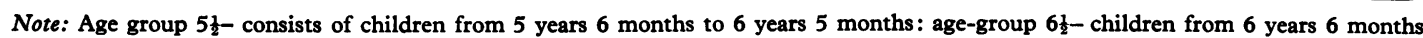
to 7 years 5 months; and so on. 
TABLE III

Distribution of Sighted Subjects in Age-groups

\begin{tabular}{c|c|c|c|c|c|c|c|c|c|c|}
\hline & \multicolumn{3}{|c|}{ Age-groups (yr.) } \\
\hline $5 \frac{1}{2}-$ & $6 \frac{1}{2}-$ & $7 \frac{1}{2}-$ & $8 \frac{1}{2}-$ & $9 \frac{1}{2}-$ & $10 \frac{1}{2}-$ & $11 \frac{1}{2}-$ & $12 \frac{1}{2}-$ & $13 \frac{1}{2}-$ & $14 \frac{1}{2}+$ \\
\hline 6 & 5 & 4 & 6 & 8 & 5 & 7 & 6 & 8 & 5 \\
\hline
\end{tabular}

random from these schools, in the age range 5 years 6 months to 15 years 5 months.

Table III shows the age distribution.

Method. Each child was given the Williams Intelligence Test Scale. This is an individual intelligence test, given orally, of the Simon-Binet type; in fact, over two-thirds of its 100 items are identical with those from either Form L or $M$ of the Terman-Merrill 1937 revision of the Binet Test. Some of its other items are from tests previously standardized on large groups of sighted subjects. Items are predominantly verbal. The scale was standardized on a population sample of children from schools for the blind and for the partially sighted. In the sample, there were approximately 300 children who were virtually blind, and 620 with some vision, 380 of the latter being at schools for the blind and 240 at schools for the partially sighted. The test was so constructed that it would be valid for use in measuring the intelligence of all children with a visual handicap, whether the loss of vision was total or only partial. In order to test its validity for this purpose, before the standardization on the complete sample was carried out, two separate standardizations were made, one on the blind and the other on the subjects who had some sight. The separate standardizations produced norms so substantially equivalent that it was evident that a scale based on norms from a joint standardization would be valid for both blind subjects and those with some sight. The joint standardization produced a scale with an average reliability coefficient of 0.94 for age levels from 6 to 15 years. Validity indices (by upper and lower thirds) of individual items range from 50 to 89. Since its publication (1956) it has been widely used to test the visually defective. Within the age range from 6 to 15 years it appears to discriminate effectively between all degrees of mental ability from the retarded (IQ 50) to the very bright (IQ 150). The mean IQ is 100 , and the standard deviation 15.

\section{Results}

The results obtained on the Williams Intelligence Test are shown in Table IV and in the Fig.

\section{Discussion}

These IQ results undoubtedly confirm the opinion long held by teachers of the blind that children blinded from retinoblastoma are intellectually superior. In the group of retinoblastoma children the greater proportion ( $78 \%$ ) were above average (IQ 110 to 142). Mean IQ was found to be $119 \cdot 7$.

What possible hypotheses may be formulated to account for the disproportionate link in this particular group between retinoblastoma and high IQ? One might consider possibilities arising from: (1) any statistical sampling bias; (2) any biological consequences of the disease.

Sampling. First, how representative was the group of the entire population of retinoblastoma children? Those tested were virtually the complete blind school population, in the age range 5 years 6 months to 15 years 5 months. What cases then have not been sampled? Those not tested were: (a) outside the age-range selected; (b) in schools for the additionally handicapped; (c) in ordinary sighted schools, the majority of which would be unilateral cases of retinoblastoma (a very small number might be bilateral which had been successfully treated); (d) cases in which death had occurred in early infancy.

Each of these categories must now be considered.

Age limits. The age range 5 years 6 months to

TABLE IV

Means, Standard Deviations, and Differences in IQ Between Groups on the Williams Intelligence Test

\begin{tabular}{|c|c|c|c|c|c|c|c|}
\hline Group & No. & Mean IQ & SD & SE of Mean & $\begin{array}{c}\text { Differences in } \\
\text { Mean IQ Between }\end{array}$ & 't' & $\begin{array}{c}\text { Significance } \\
\text { Levels }\end{array}$ \\
\hline $\begin{array}{l}\text { (a) Retinoblastoma } \\
\text { (b) Non-retinoblastoma } \\
\text { (c) Sighted } \ldots\end{array}$ & $\begin{array}{l}50 \\
74 \\
60\end{array}$ & $\begin{array}{l}119 \cdot 72 \\
102 \cdot 81 \\
102 \cdot 67\end{array}$ & $\begin{array}{r}9 \cdot 76 \\
15 \cdot 96 \\
12 \cdot 01\end{array}$ & $\begin{array}{l}1 \cdot 39 \\
1 \cdot 87 \\
0 \cdot 56\end{array}$ & $\begin{array}{l}a \sim b: 16 \cdot 91 \\
a \sim c: 17 \cdot 05 \\
b \sim c: 0.14\end{array}$ & $\begin{array}{l}7 \cdot 35 \\
8 \cdot 23 \\
0 \cdot 57\end{array}$ & $\begin{array}{l}\mathrm{p}<0.001 \\
\mathrm{p}<0.001 \\
\text { Not sig. }\end{array}$ \\
\hline
\end{tabular}




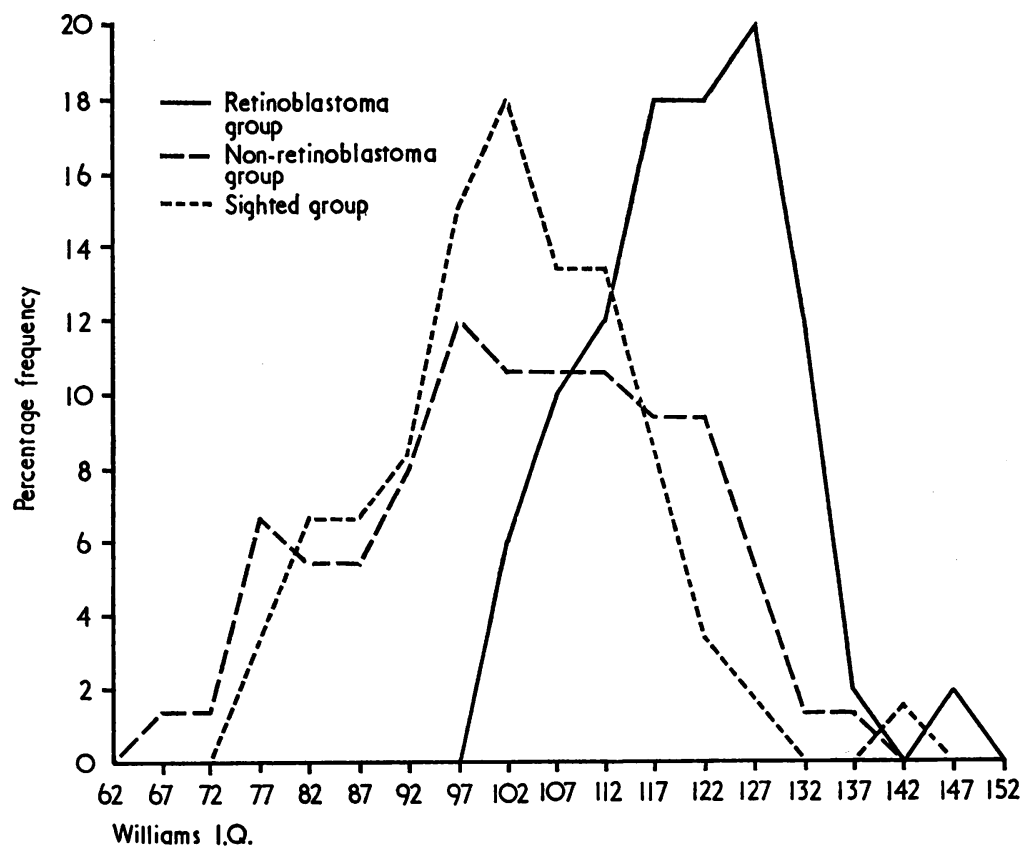

FIG.-Comparative frequency distribution of IQs of 50 children blinded by retinoblastoma, 74 children blinded by causes other than retinoblastoma, and 60 sighted children.

15 years 5 months was selected, because at ages below $5 \frac{1}{2}$ years an intelligence test result is not generally considered to have as much predictive value as it does later, and at ages above 16 years the sample would have been biased, inasmuch as it is the brighter children at grammar school who are inclined to stay on and continue their education. As suggestive evidence of the probable intellectual level of the preschool group, however, it is interesting to note that the behaviour of the young children blinded from retinoblastoma who are either at home or in one of the nursery schools of the R.N.I.B., as reported by those who come into contact with them, indicates that they are bright and lively youngsters, decidedly above average intellectually. At the other end of the age scale it may be noted that at the time of this inquiry $16 \%$ of the pupils at grammar schools for the blind over the age of 16 years were young people blinded from retinoblastoma. There is thus no reason to suppose that the selected age range was not typical, as regards intelligence, of all ages under 20.

Inclusion of additionally handicapped. Since the main interest in this inquiry was focused on the association of retinoblastoma with intelligence, to have included cases in which some additional handicap was present would have blurred the issue.
It might be interesting to note that in the R.N.I.B. schools for the additionally handicapped blind (Leamington Spa, Overley, Rushton, and Condover) at the time of the inquiry there was only one case of retinoblastoma. In the ordinary blind schools only one case of retinoblastoma had to be excluded, that of a boy with a considerable hearing defect.

Omission of unilateral cases. Is it likely that the missing range of average and below-average IQ's from the sample of retinoblastoma children tested would be found in the unilateral cases of retinoblastoma, children presumably in sighted schools? It would certainly be interesting to obtain their IQ's on the same test. But it can hardly be expected that a random sample would consist of average and below average IQ's. Such an association between high intelligence and bilateral retinoblastoma on the one hand, and between low or average intelligence and unilateral retinoblastoma on the other, would be no less mysterious than the relationship of high IQ with the retinoblastoma population as a whole.

Selection by survival. Mortality, unfortunately, occurs in a certain percentage of retinoblastoma cases. There is no possibility of assessing the intellectual level of infants who have died of the 
disease. Is it possible that these fatalities have occurred differentially over the IQ range? It is perhaps conceivable that the retinoblastoma children of the more intelligent parents stand a better chance of survival through early recognition of symptoms and prompt medical attention. Yet, not all the children of intelligent parents are of high intelligence -nor would it seem likely that the retinoblastoma would pass unnoticed in the children of all less able parents.

It is conceivable that it is the fitter physically who survive when retinoblastoma strikes. It is relevant to note here Fraser's findings given in his report Causes of Blindness in Childhood (1967). The Report, drawing attention to the intellectual superiority of retinoblastoma children, tentatively associates this with the slight excess found in the mean birthweight of the retinoblastoma group over the control group: 'This excess over the control figure could be due to chance, but an alternative explanation is that the high birthweight and high intelligence of children with bilateral retinoblastoma may be positively correlated both with each other and with social class which may favourably affect their chance of survival.'

Further supporting evidence of a positive correlation between high birthweight and intelligence is given in the concluding chapter of the Report in the finding of a rank correlation coefficient of 0.657 between the intellectual attainment and the birthweight of 721 children (blinded from various causes including retinoblastoma), a coefficient significantly different from zero at the $1 \%$ level of probability.

Can we, then, take the above factors: intelligent parents, physical fitness, above-average birthweight, and good social background as being sufficient of themselves to account for the high mean IQ of $119 \cdot 7$ of our retinoblastoma group ? That such an interplay of favourable factors would be responsible for, at least, very good average intelligence is highly probable, but whether it can be claimed responsible for an excess of almost 20 points above the population mean of the sample upon which the Williams Test was standardized seems dubious.

Secondly, how representative was the nonretinoblastoma group of the entire population of children blinded from causes other than retinoblastoma? This group, consisting of $10 \%$ of the blind school population, included all types of visual defect. As with the retinoblastomas, and for identical reasons, those not sampled were the children outside the age limits and those in schools for the additionally handicapped blind. Retrolental fibroplasia was, at the time of this inquiry, the largest single cause of blindness in schools for the blind, and this is reflected in the randomized sample, $32 \%$ of its intake being cases of retrolental fibroplasia. It may be surmised that this would bias the sample, inasmuch as retrolental fibroplasia, associated as it is with prematurity and its subsequent handicaps, may be found with low IQ. Let us consider this possibility.

The number of retrolentals in the sample was 24, too small for any reliable statistics to be presented. But it is interesting to note that the results of the Williams Intelligence Test gave IQs ranging from 73 to 124 , with a mean IQ of just over 100 . There is nothing unusual here; similar results may be expected from any group of children. Thus, it can be assumed that no statistical bias was given by the disproportionate number of children in the sample blinded from retrolental fibroplasia.

The mean IQ of the total sample of non-retinoblastomas was $102 \cdot 8$, which varies little from the population mean of the sample upon which the Williams Intelligence Test was standardized, and certainly gives no reason to suppose that the sample in this inquiry was not representative of the entire population of non-retinoblastoma children in ordinary schools for the blind.

On the same test, then, the retinoblastoma children scored approximately 17 points higher than a random sample of non-retinoblastoma children of average intelligence.

There remains the possibility of bias in the sample of sighted children. Though randomized, the sample was very small and the number of schools selected extremely limited, so care must be taken not to read too much into the results. It must be considered whether there is any evidence to suggest that the sample was of average intelligence. It may be thought that since the Williams test is entirely orally administered and orally responded to, and was specifically devised for the visually handicapped, the IQ of $102 \cdot 7$ obtained from the sighted sample cannot be taken as valid evidence that the sighted sample is of average intelligence. Yet about twothirds of the subjects in its standardization population had some sight. Furthermore, nearly $70 \%$ of the content of the Williams Intelligence Test is identical with that of the 1937 revision of the Stanford-Binet Test for the sighted, which, too, is orally administered. Therefore, the Williams mean IQ of $102 \cdot 7$ is likely to be a fairly close approximation to the probable mean IQ of these sighted children on any standard sighted test of the Binet type. And if this is so, the fact that the mean IQ of these children would probably be about 100 suggests that the sample, though so small, was 
fairly representative of the sighted population as a whole.

The really significant comparison which can now be presented is that on the same test, retinoblastoma children score 17 points of IQ higher than a randomly chosen sample of 60 sighted children of average intelligence. Here, the superior intelligence of the retinoblastoma group is shown in relation to normal sighted children.

Biological implications. Retinoblastoma is one of the few causes of blindness in which there is no other involvement of the central nervous system, and is thus termed a 'clean condition'. Therefore, there would be no reason to expect that the retinoblastoma group (like those blinded by some other diseases) would have less than average ability. Forrester (1964), a paediatrician of the R.N.I.B. with particularly wide experience of blind children states: 'Of all the causes of blindness in young children the retinoblastoma is the one in which the child is allowed to avoid: (a) premature birth and its subsequent handicaps; (b) brain damage and its associated neurological disorders; the disorder is confined to the eye; (c) many of these children did have some sight for months or even a year or more. This may just have been sufficient to lift them over the impenetrable barrier which other congenitally blind children cannot surmount. The scales are weighted in favour of the retinoblastoma child just as they are weighted against the average child with other forms of congenital blindness; I think this explains the difference.'

This undoubtedly goes some way towards explaining the difference intellectually between the child blinded from retinoblastoma and from other causes. For example, supporting evidence of (b) is clearly given by the fact that there was, at the time of this inquiry, only one case of retinoblastoma amongst the total population of blind children in schools for the additionally handicapped blind, schools that altogether cater for well over 100 children. There is an obvious contrast between the negligible association of retinoblastoma with additional handicap, and the considerable association of blindness from other causes with additional handicap, at any rate in the school population.

As far as (c) is concerned, it would not be easy to collect objective evidence to prove or disprove the claim, as it is often difficult to establish the exact time of onset of blindness and, particularly with younger children, its extent. It is certainly only reasonable to assume that remembered vision from the early months gives advantages which help intellectual development, so that those blind from birth appear to develop at a slower rate than those blinded later. However, the retinoblastomas are by no means the only children who have had sight for some months or longer, for there were 29 children in the non-retinoblastoma group who actually enjoyed some degree of useful sight at the time they were tested.

In regard to (a), the importance attached by Forrester to the general absence of prematurity in the case of retinoblastoma children, the following observations may be considered. The eye defect associated with prematurity is retrolental fibroplasia. Hayes (1952) in his comparison of 65 retrolental infants with 141 non-retrolentals tested with the Interim Hayes Binet Intelligence Test found the distribution of IQs showed the same normal form, with equal percentages of cases in the superior, high average, and average groups, but smaller percentages appeared in the borderline and mentally defective groups for the retrolentals. When the retrolental pupils at the Perkins School for the Blind were compared with the non-retrolentals a similar superiority was found.

At the time of this inquiry (1965) it so happened that the majority of the retrolentals in the school population were at the secondary stage of their education. It is interesting to note that at that time $12 \%$ of all the boys at Worcester College and almost $25 \%$ of all the girls at Chorleywood College, two R.N.I.B. grammar schools for the blind, were retrolentals (see footnote to Table I).

In trying to find possible explanations for the intellectual brightness of the retinoblastomas, a query has been raised as to whether it could be attributed in any way to an effect of the treatment of the disease. A common experience of retinoblastoma survivors will have been treatment by some form of radiation. Speculations are here unprofitable and it is mentioned here only for the sake of completeness in the argument. And, in any case, the high intelligence of retinoblastoma children had been noted (though not reliably measured) before the current methods of radiation had been adopted.

There remains another possibility. The hereditary nature of retinoblastoma is a fact; so (in some measure) is intelligence. Is there any genetic mechanism whereby a predisposition to this particular type of retinal tumour could also predispose to high intellectual development? This is, perhaps the most fascinating of all the possibilities, yet (so far as the writer can discover) there is not the slightest evidence to support such a supposed mechanism.

Thus, the mystery of the undoubted intellectual superiority of the retinoblastoma survivors remains. 


\section{Summary}

Children blinded from retinoblastoma, and who were at blind school, were of either average or above average intelligence, the number above average exceeding the number of average intelligence when tested on the Williams Intelligence Test Scale.

A group of children blinded from causes other than retinoblastoma were also tested, and it was shown that the retinoblastoma children had a significantly higher IQ.

A group of sighted children from four normal schools were tested on the same Test Scale; the retinoblastoma children scored 17 points of IQ higher than the sighted children.

A search for some explanation that might account for the superiority of the retinoblastoma children in respect of intelligence led to no wholly satisfactory hypothesis.
I wish to acknowledge the help of Mr. W. Curr, Senior Lecturer in Education, and Dr. J. N. Langdon, Senior Research Fellow, School of Education, University of Birmingham, and the Chairman, Mr. S. O. Myers, and members of the College of Teachers of the Blind Research Committee.

\section{REFERENCES}

Dollfus, M. A., and Auvert, B. (1953). Le Gliome de la Rétine (Rétinoblastome) et les Pseudogliomes. Masson, Paris.

Forrester, R. (1964). Changing pattern of blindness in young children. Teacher of the Blind, 53, 1, 10.

Francois, J. (1961). Heredity in Ophthalmology. C. V. Mosby, St. Louis.

Fraser, G. (1967). Causes of Blindness in Childhood, Godfrey Memorial Research. Johns Hopkins Press, Baltimore.

Hayes, S. P. (1952). First Regional Conference on Mental Measurement of the Blind (Perkins Publications, no. 15), pp. 27-30. Perkins Institution, Watertown, Massachusetts.

Sorsby, A. (1966). The Incidence and Causes of Blindness in England and Wales 1948-62. Reports on Public Health and Medical Subjects. No. 114, p. 60 . H.M.S.O., London.

Williams, M. (1956). Williams' Intelligence Test for Children with Defective Vision. University of Birmingham, Institute of Education. 